\title{
Centro de Estudios Sociales Interdisciplinarios del Litoral (CESIL)
}

\author{
María Luisa D Angelo (1)
}

(1) Directora del CESIL.
El Centro de Estudios Sociales Interdisciplinarios del Litoral (CESIL) es una unidad académica dependiente de la Facultad de Humanidades y Ciencias de la UNL que se propone como actividades básicas el desarrollo de la investigación, la participación en la enseñanza superior y la divulgación y promoción de actividades científicas en el ámbito de la disciplinas que integran el campo del conocimiento social.

Constituye un espacio de trabajo académico basado en el intercambio de saberes y experiencias de un grupo de docentes-investigadores, en cuyos equipos de trabajo actúan también alumnos y graduados, de Historia, Geografía y Letras, La integración y la producción se enmarcan en el desarrollo de Programas de investigación promovidos y evaluados por la Universidad. Las actuales autoridades del CESIL son las que se consignan a continuación:

- Directora: Prof. Mgt. María Luisa D’Angelo

- Vicedirectora: Prof. Elsa Ghio

- Vocales: Prof. Alberto Bartolini, Prof. Luciano Alonso y Prof. Mgt. Fabián Mónaco 
Integran del centro dos docentes-investigadores con categoría I, ocho con categoría II y diez con categoría III. Cuenta además con tres docentes-investigadores del CONICET y ocho becarios de posgrado (UNL, CONICET, ANCYP).

Los distintos equipos están desarrollando los siguientes proyectos de investigación y desarrollo evaluados y aprobados por los organismos de la universidad:

- Acción y dispositivos de control social en el escenario santafesino.

- Impacto territorial de los cambios y permanencias de la estructura agraria de la provincia de Santa Fe a partir de los 90 y sus consecuencias demográficas.

- La continuidad política en los cargos ejecutivos en municipios y comunas y su relación con el financiamiento del sector público en la provincia de Santa Fe entre 1983 y 2005.

- Procesos de aglomeración y dinámica territorial del desarrollo. Análisis comparado de enfoques teóricos dominantes e identificación empírica de aglomeraciones industriales pertenecientes a ramas relevantes en la provincia de Santa Fe en los períodos intercensales 1985/1994/2005.

- Dinámica demográfica de la provincia de Santa Fe. Período 1991-2001.

- Migraciones, filiaciones y trascendencia en las narrativas en lengua española en los siglos XX y XXI.

- Travesías del sentido/indagaciones narrativas.

- Contextos plurilingües: discursos, representaciones y prácticas.

- Contexto sociohistóricos de uso del español en Argentina. Registros y géneros escritos.

La revista "Texturas. Estudios interdisciplinarios sobre el Discurso" es una publicación periódica del CESIL.

Otra publicación, realiza entre 1997 y 2000, la constituyó la serie de "Temas de Humanidades" que difundió trabajos de los integrantes del Centro y de invitados externos, la intención de contribuir a la reflexión sobre temas relevantes para las Ciencias Sociales y para la actividad docente asociada a cada campo disciplinar. 
En lo que refiere a tareas de extensión, los integrantes de cada equipo de investigación han participando en eventos académicos provinciales, nacionales e internacionales exponiendo los resultados de su trabajo y han dictado cursos de actualización docente en función de temáticas abordadas en sus proyectos.

Durante el presente año académico se debate la generación de nuevos grupos de trabajo para el abordaje de estudios latinoamericanos, de problemáticas sociales contemporáneas y para dinamizar la inserción del Centro en el contexto social, estableciendo contactos con instituciones santafesinas. 